\title{
Managing obsessive compulsive disorder
}

\section{SUMMARY}

Unlike obsessive compulsive personality traits or occasional repetitive habits, obsessive compulsive disorder can be highly distressing and associated with significant disability. Treatment should always be offered.

Psychological interventions and selective serotonin reuptake inhibitors are first-line treatments for obsessive compulsive disorder.

Patients with obsessive compulsive disorder respond to selective serotonin reuptake inhibitors at a slower rate than those with depression.

The dose of a selective serotonin reuptake inhibitor can be increased at two-week intervals depending on the patient's response. Aim for doses in the higher therapeutic range.

Improvements from treatment usually plateau at 12 weeks.

Successful treatment should continue for at least 12 months. There is a significant risk of relapse when treatment is stopped.

\section{Introduction}

Obsessive compulsive disorder (OCD) is a common and disabling condition. It occurs in approximately $2 \%$ of the population and $6-8 \%$ of people have subclinical symptoms.?

$O C D$ is characterised by recurrent and intrusive thoughts, images or impulses (obsessions) that are distressing, accompanied by repetitive behaviours or compulsions. In most cases, patients see their symptoms as senseless or unreasonable, but they have difficulty resisting them. The repetitive behaviours, distress and indecisiveness can lead to obsessional slowness and avoidance. It is ranked as one of the top 10 most disabling medical conditions. ${ }^{2}$ Patients tend to disclose their symptoms to their GP after many years of suffering in silence. ${ }^{3}$ They are often embarrassed by their symptoms and may fear that their symptoms will be seen as trivial. They might also believe there is no effective treatment.

$O C D$ is difficult to screen for as it can present with a variety of symptoms, including:

- doubt and checking

- contamination fears and cleaning

- the need to have objects symmetrical or in order

- unacceptable aggressive, sexual or religious intrusive thoughts.

It is often confused with obsessive compulsive personality disorder (anankastic personality disorder) in which perfectionism, orderliness and rigidity is an egosyntonic or non-distressing aspect of personality. The personality disorder does not always accompany OCD. ${ }^{4}$

\section{Psychological interventions}

Patients often fear adverse effects associated with drug treatment, or the risk of drug dependency. They will therefore often request psychological strategies to assist them to resist and cope with their symptoms. Of the many psychological treatments that are available, exposure and response prevention has the most evidence for its effectiveness. ${ }^{5}$

Exposure and response prevention therapy involves exposing patients to their fears and preventing their response (or their compulsion). For example, a person with contamination obsessions is asked to touch something that they deem contaminated (exposure) and would normally avoid. The patient is then taught to manage their anxiety without using washing or cleaning compulsions (response prevention). Exposure should be conducted in a graded manner with exposure to less anxiety-provoking stimuli in the initial stages.

Internet-based treatment programs* based on cognitive behavioural therapy can also be beneficial. In clinical trials, both therapist-guided and self-guided programs were effective. ${ }^{6}$ This may be particularly useful for those in rural and remote areas.

\section{Drug treatments}

Pharmacological interventions are recommended when patients are unable to face the prospect of

* Examples include www.OCDSTOP.org.au and https://thiswayup.org.au/clinic/courses/courses-weoffer/obsessive-compulsive-disorder.
Vlasios Brakoulias

Conjoint senior lecturer Psychiatry Sydney Medical School University of Sydney

\section{Key words}

antidepressants, anxiety disorders, cognitive behavioural therapy, obsessive compulsive disorder

Aust Prescr 2015;38:121-3 
heightening their anxiety in exposure and response prevention, when they have severe symptoms and when they are unable to access an appropriately trained psychologist.? It may be difficult to find a psychologist with adequate experience of OCD or waiting lists may be long. The cost of psychological counselling is also a commonly reported problem.

The evidence for drug treatment is robust (see Table). ${ }^{8}$ Most patients will have some alleviation of their symptoms. Some studies indicate that $50 \%$ of people will achieve remission when treated with a selective serotonin reuptake inhibitor (SSRI). ${ }^{9}$

Treatment usually commences with an SSRI (see Table). Response rates are similar between drugs ${ }^{10}$ so the choice of which one to prescribe is usually determined by the doctor's familiarity with an SSRI or by the need to reduce the risk of drug interactions. Trials have not convincingly proven the superiority of clomipramine over SSRIs. Although clomipramine can be effective for some patients, it is usually used after two failed trials of an SSRI due to problems with the tolerability of clomipramine. ${ }^{7}$ Unlike other anxiety disorders, OCD tends not to respond to benzodiazepines."

Some patients respond to standard doses of SSRIs, however most will need higher doses. ${ }^{12,13}$ Doses used in trials are listed in the Table. Patients prescribed higher doses should be informed of this and monitored carefully in consultation with a psychiatrist. They should also be warned that response to treatment may be slow and the full effect of their medication may only become evident after 12 weeks. It is usually recommended that SSRIs

\section{Table Drug treatments for OCD}

\begin{tabular}{ll} 
Drug & Dose range used in studies \\
\hline Citalopram ${ }^{\dagger}$ & $20-80 \mathrm{mg} /$ day \\
Escitalopram & $10-40 \mathrm{mg} /$ day \\
Fluoxetine & $40-80 \mathrm{mg} /$ day \\
Fluvoxamine & $50-300 \mathrm{mg} /$ day \\
Paroxetine & $20-60 \mathrm{mg} /$ day \\
Sertraline & $50-200 \mathrm{mg} /$ day \\
Clomipramine & $75-300 \mathrm{mg} /$ day \\
\hline only recommended up to $40 \mathrm{mg} /$ day
\end{tabular}

are increased every two weeks depending on the individual's response and how they tolerate the medication. Based on response rates in multiple studies, ${ }^{8}$ an SSRI should be trialled at its maximum dose for at least 12 weeks before concluding it is ineffective.

It is generally recommended that successful treatment with an SSRI should be continued for at least 12 months. Several studies have shown that patients continue to benefit during this period. ${ }^{14,15} \mathrm{~A}$ decision to cease successful treatment should be considered carefully as most studies report relapse rates of over $50 \%$ within 12 weeks. ${ }^{16}$ A patient's life circumstances will need to be evaluated to gauge the risk of relapse and the effect it may have on them. Withdrawing an SSRI should occur slowly, over several months, and preferably with guidance from a psychiatrist when symptoms have been severe.

Combining exposure and response prevention therapy with an SSRI has been shown to be more effective than either alone. ${ }^{16}$ When a patient does not respond to pharmacotherapy, adding exposure and response prevention therapy is usually recommended. Treament-resistant patients should be referred to a psychiatrist. Deep brain stimulation is used as a treatment of last resort in Australia but is prohibited under the NSW Mental Health Act (2007).

\section{Adverse effects and drug interactions}

Prescribers should be aware of the risks associated with prescribing high-dose SSRIs. Patients should be monitored for signs of serotonin syndrome and warned that concomitant St John's wort or tramadol frequently cause it and should be avoided.

High-dose SSRIs and clomipramine can cause prolonged QT and arrhythmias and so regular ECGs are recommended following a dose escalation. Fluoxetine and paroxetine are both potent inhibitors of cytochrome P450 2D6 and clomipramine inhibits several cytochrome P450 enzymes.

\section{Conclusion}

OCD can be treated with exposure and response prevention, SSRIs or both. Treatment requires some patience (and perseverance in the case of exposure and response prevention), but significant improvements can be achieved. $<$

Conflict of interest: none declared 
1. Karno M, Golding JM, Sorenson SB, Burnam MA. The epidemiology of obsessive-compulsive disorder in 5 US communities. Arch Gen Psychiatry 1988;45:1094-9.

2. Eaton WW, Martins SS, Nestadt G, Bienvenu OJ, Clarke D, Alexandre P. The burden of mental disorders. Epidemiol Rev 2008;30:1-14.

3. Subramaniam M, Abdin E, Vaingankar JA, Chong SA. Obsessive-compulsive disorder: prevalence, correlates, helpseeking and quality of life in a multiracial Asian population. Soc Psychiatry Psychiatr Epidemiol 2012;47:2035-43.

4. Starcevic V, Berle D, Brakoulias V, Sammut P, Moses K, Milicevic $D$, et al. Interpersonal reassurance seeking in obsessive-compulsive disorder and its relationship with checking compulsions. Psychiatry Res 2012;200:560-7.

5. Franklin ME, Foa EB. Treatment of obsessive compulsive disorder. Annu Rev Clin Psychol 2011;7:229-43.

6. Wootton BM, Dear BF, Johnston L, Terides MD, Titov N. Self-guided internet administered treatment for obsessivecompulsive disorder: results from two open trials. J Obsessive Compuls Relat Disord 2014;3:102-8.

7. National Collaborating Centre for Mental Health (UK) Obsessive-compulsive disorder: core interventions in the treatment of obsessive-compulsive disorder and body dysmorphic disorder. NICE Clinical Guidelines, No. 31. Leicester (UK): British Psychological Society; 2006.

8. Marazziti D, Consoli G. Treatment strategies for obsessivecompulsive disorder. Expert Opin Pharmacother 2010;11:331-43.

9. Simpson HB, Huppert JD, Petkova E, Foa EB, Liebowitz MR. Response versus remission in obsessive-compulsive disorder. J Clin Psychiatry 2006;67:269-76.
10. Ackerman DL, Greenland S. Multivariate meta-analysis of controlled drug studies for obsessive-compulsive disorder. J Clin Psychopharmacol 2002;22:309-17.

11. Bossini L, Borghini E, Fagiolini A. [Clinical uses of benzodiazepines. Focus on: benzodiazepines and anxiety disorders]. J Psychopathol 2013;19:272-86. Italian.

12. Ninan PT, Koran LM, Kiev A, Davidson JR, Rasmussen SA Zajecka JM, et al. High-dose sertraline strategy for nonresponders to acute treatment for obsessive-compulsive disorder: a multicenter double-blind trial. J Clin Psychiatry 2006;67:15-22.

13. Rabinowitz I, Baruch Y, Barak Y. High-dose escitalopram for the treatment of obsessive-compulsive disorder. Int Clin Psychopharmacol 2008;23:49-53.

14. Tollefson GD, Rampey AH Jr, Potvin JH, Jenike MA, Rush AJ, Dominguez RA, et al. A multicenter investigation of fixeddose fluoxetine in the treatment of obsessive-compulsive disorder. Arch Gen Psychiatry 1994;51:559-67.

15. Greist JH, Jefferson JW, Kobak KA, Chouinard G, DuBoff E, Halaris A, et al. A 1 year double-blind placebo-controlled fixed dose study of sertraline in the treatment of obsessivecompulsive disorder. Int Clin Psychopharmacol 1995;10:57-65.

16. Simpson HB, Liebowitz MR, Foa EB, Kozak MJ, Schmidt AB, Rowan V, et al. Post-treatment effects of exposure therapy and clomipramine in obsessive-compulsive disorder. Depress Anxiety 2004;19:225-33.

\section{FURTHER READING}

NSW Government Health, Nepean Blue Mountains Local Health District. Obsessive-compulsive disorder (OCD): a general information guide. Sydney: University of Sydney; 2015. www nbmlhd health nsw.gov.au/ArticleDocuments/434/

OCD-booklet-March-2015.pdf.aspx [cited 2015 Jul 1]

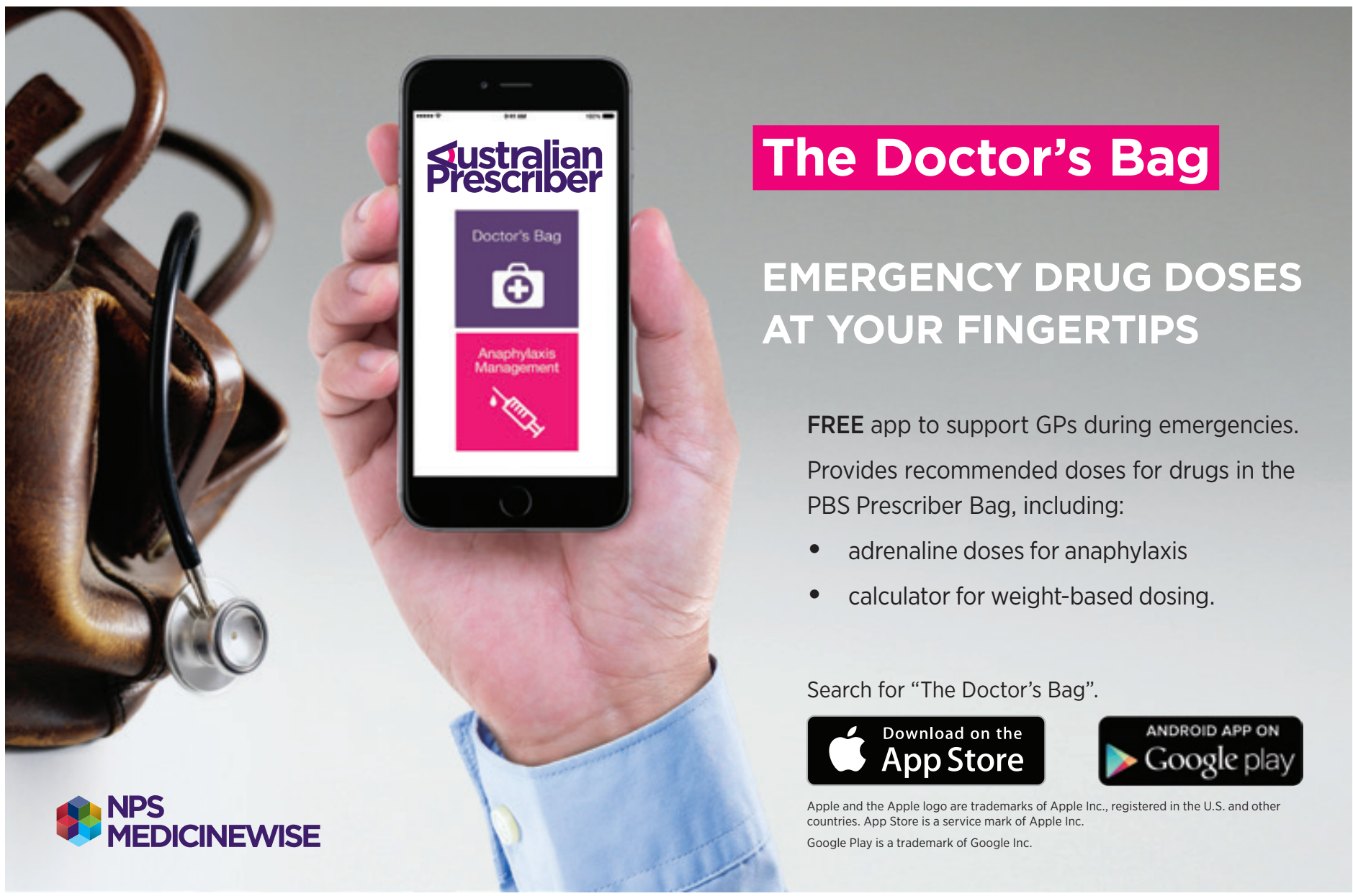

